Check for updates

Cite this: Nanoscale Adv., 2019, 1 , 4989

Received 17th October 2019

Accepted 16th November 2019

DOI: $10.1039 / c 9 n a 00658 c$

rsc.li/nanoscale-advances

\title{
Nano- $\mathrm{SiO}_{2}$ coating enabled uniform $\mathrm{Na}$ stripping/ plating for dendrite-free and long-life sodium metal batteries $\uparrow$
}

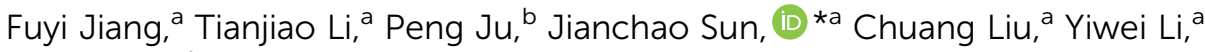 \\ Xueqin Sun ${ }^{\star a}$ and Chengcheng Chen $^{\mathrm{c}}$
}

\begin{abstract}
Metallic sodium, which has a suitable redox potential and high theoretical capacity, is regarded as an ideal anode material for rechargeable $\mathrm{Na}$ metal batteries. However, dendrite growth on sodium metal during cycling has seriously restricted its practical applications. Herein, we employed a low-cost and facile brushing method to fabricate a porous nano- $\mathrm{SiO}_{2}$ coating, which can induce a relatively uniform distribution of $\mathrm{Na}^{+}$flux and suppress the growth of $\mathrm{Na}$ dendrites. The nano- $\mathrm{SiO}_{2}$ coating with high porosity can decrease the $\mathrm{Na}$ stripping/plating overpotential $(<50 \mathrm{mV})$ over 400 cycles at $5 \mathrm{~mA} \mathrm{~cm}{ }^{-2}$. Moreover, when coupled with a $\mathrm{Na}_{3} \mathrm{~V}_{2}\left(\mathrm{PO}_{4}\right)_{3}$ (NVP) cathode, the $\mathrm{Na}$ with $\mathrm{SiO}_{2}$ coating $\left(\mathrm{Na}\left(\mathrm{SiO}_{2}\right)\right.$ composite anode shows a favorable suitability in a full cell. Compared with the one with a bare $\mathrm{Na}$ anode, the full cell with the $\mathrm{NaCSiO}_{2}$ anode delivers a $27.8 \%$ higher discharge capacity $(94.6$ vs. $74 \mathrm{~mA} \mathrm{~h} \mathrm{~g}^{-1}$ at $1 \mathrm{C}$ ) after 1000 cycles.
\end{abstract}

\section{Introduction}

Nowadays, as fossil fuel-related energy is consumed excessively and environmental awareness boosts, the demand for alternative clean energy is becoming more and more urgent. ${ }^{\mathbf{1 - 4}}$ Over the past few decades, rechargeable lithium-ion batteries (LIBs) have dominated portable electronics, medical microelectronics, and electric vehicles (EVs) as one of the most promising energy storage systems. ${ }^{5-9}$ However, with the increasing demand for LIBs and shortage of lithium resources, the cost of lithium raw materials has increased rapidly. ${ }^{\mathbf{1 0 - 1 2}}$ Therefore, researching and exploring substitutes for LIBs has become one of the significant directions in the development of rechargeable batteries. ${ }^{13-15}$ Because of the abundant reserves, low cost, and suitable electrochemical potential of $\mathrm{Na}$, rechargeable $\mathrm{Na}$ batteries have received widespread attention and are regarded as the most promising substitute to LIBs. ${ }^{\mathbf{1 6 - 2 0}}$ However, some serious problems have hampered the practical application of rechargeable $\mathrm{Na}$ batteries. ${ }^{21}$ The charge and $\mathrm{Na}^{+}$distribution on the surface of sodium metal are non-uniform during continuous chargedischarge cycling, resulting in the formation of sodium

${ }^{a}$ School of Environment and Materials Engineering, Yantai University, Yantai, Shandong 264005, China. E-mail: jianchaoabc@163.com; sxq@ytu.edu.cn

${ }^{b}$ Key Laboratory of Marine Bioactive Substances and Analytical Technology, Marine Ecology Center, First Institute of Oceanography, Ministry of Natural Resources (MNR), Qingdao, Shandong 266061, China

'Key Laboratory of Advanced Energy Materials Chemistry (Ministry of Education), College of Chemistry, Nankai University, Tianjin 300071, China

$\dagger$ Electronic supplementary information (ESI) available. See DOI: $10.1039 / \mathrm{c} 9 \mathrm{na} 00658 \mathrm{c}$ dendrites. ${ }^{22,23}$ The dendrites not only affect the capacity and life of batteries, but cause safety problems such as short-circuits and explosions, hindering the practical application of sodium metal batteries (SMBs). ${ }^{\mathbf{2 4 , 2 5}}$ Therefore, solving the problem of $\mathrm{Na}$ metal dendrites generated during charge-discharge cycling is the key to improving the cycling stability and accelerating the commercial application of Na metal anodes. ${ }^{26}$

Recently, many methods have been adopted to restrain dendritic Na formation, including (1) the stabilization of the SEI layer by electrolyte modification; ${ }^{27-29}$ (2) engineering artificial SEI layers by surface modification, $;^{30-32}$ and (3) engineering nanostructured current collectors and hosts by artificial manufacture. ${ }^{33-35}$ For instance, Wang and co-workers designed potassium bis(trifluoromethylsulfonyl)-imide (KTFSI) as a bifunctional electrolyte additive to stabilize the $\mathrm{Na}$ metal electrode. ${ }^{36}$ In the work reported by Sun's group, an ultrathin protective coating was constructed as a protective layer on a $\mathrm{Na}$ metal anode through the ALD technique. ${ }^{21}$ Luo' group stabilized $\mathrm{Na}$ metal anodes by employing a porous $\mathrm{Al}$ current collector as the plating substrate. ${ }^{37} \mathrm{Hu}$ and co-workers manufactured a stable Na-carbonized wood composite anode as a 3D host for $\mathrm{Na}$ metal. ${ }^{38}$ These strategies provide insights for $\mathrm{Na}$ metal protection and achieve excellent electrochemical performance. Unfortunately, the expensive and complex preparation process poses substantial obstacles to the practical application of these strategies. Recently, Chen and Kang's group have designed nano-Super $\mathrm{P}$ and nano- $\mathrm{CaCO}_{3}$ coatings respectively, which restrain the growth of $\mathrm{Li}$ and $\mathrm{Zn}$ dendrites. ${ }^{39,40}$ Inspired by this, we explored a low-cost, simple, safe and scalable strategy to 
inhibit the growth of non-uniform dendrites in the $\mathrm{Na}$ metal anode.

Herein, we report a simple method to construct a porous nano-SiO $\mathrm{S}_{2}$ coating as an auxiliary layer for inhibiting the growth of $\mathrm{Na}$ dendrites. We found that the nano-SiO ${ }_{2}$ coating with a high porosity can be easily permeated by electrolyte. Compared with the bare Na anode (Fig. 1a), the Na anode with the $\mathrm{SiO}_{2}$ coating induces a relatively uniform distribution of $\mathrm{Na}^{+}$ flux (Fig. 1b).

The $\mathrm{SiO}_{2}$ coating on the surface of $\mathrm{Na}$ acted as an electrolyte transport channel (like pores in water-permeable bricks), effectively dispersing $\mathrm{Na}^{+}$flux and achieving the purpose of suppressing dendrites. Consequently, the $\mathrm{Na} @ \mathrm{SiO}_{2}$ composite electrode used in symmetrical cells exhibited excellent cycling stability with significantly reduced polarization. Furthermore, $\mathrm{Na}$ dendrites were found to be absent in the $\mathrm{Na} @ \mathrm{SiO}_{2}$ electrode even at a current density of $5 \mathrm{~mA} \mathrm{~cm} \mathrm{~cm}^{-2}$ after 100 cycles. Moreover, we also tested a Na metal electrode with Super P coating, clearly finding that insulation coating $\left(\mathrm{SiO}_{2}\right)$ has advantages over conductive coating (Super P). Finally, we successfully constructed a full cell with an NVP cathode and a $\mathrm{Na@SiO}$ anode, proving the benefits of this coating strategy for potential applications.

\section{Experimental}

\section{Fabrication of $\mathrm{Na} @ \mathrm{SiO}_{2}$ and $\mathrm{Na} @ S u p e r \mathrm{P}$ electrodes}

Firstly, a certain amount of nano $\mathrm{SiO}_{2}$ or Super $\mathrm{P}$ was dried in a vacuum oven at $60{ }^{\circ} \mathrm{C}$ for 10 hours. Then, a Na disk $(12 \mathrm{~mm}$ in diameter, $0.3 \mathrm{~mm}$ in thickness) was evenly coated with $\mathrm{a} \mathrm{SiO}_{2}$ or Super P layer $(\sim 100 \mu \mathrm{m})$ via brushing and rolling in an Ar-filled glovebox, and the mass loading of the layer is about $4.4 \mathrm{mg}$ $\mathrm{cm}^{-2}$.

\section{Structural characterization}

A scanning electron microscope (SEM, JSM-7610F) with an EDX attachment was used for obtaining SEM images and the corresponding EDX mapping images. For observing the morphology of electrodes after cycling, batteries were first disassembled in a glovebox and then the electrodes were rinsed with diglyme to remove residual $\mathrm{Na}$ salts. XRD patterns were obtained using a Rigaku D/MAX 2500/PC diffractometer with $\mathrm{Cu} \mathrm{K} \alpha$ radiation $(\lambda$ $=0.154 \mathrm{~nm}$ ). Noticeably, the Na samples for SEM tests were loaded in a sealing device and covered with Kapton tape to avoid direct contact with air.

\section{Electrochemical measurements}

To investigate the electrochemical properties of Na stripping/ plating, symmetrical 2032-type coin cells were assembled with two identical electrodes, which were either $\mathrm{Na@SiO}{ }_{2}$ or bare $\mathrm{Na}$ electrodes. For the preparation of the NVP cathode, NVP powder was mixed with carbon black and polyvinylidene fluoride (weight ratio of $8: 1: 1$ ) using $N$-methyl-2-pyrrolidone as the solvent. The mass loading of the NVP cathode is about $1 \mathrm{mg}$. The electrolyte solution was $1 \mathrm{M}$ sodium hexafluorophosphate $\left(\mathrm{NaPF}_{6}\right)$ in diglyme. All batteries were assembled in an argonfilled glovebox using the same dose of electrolyte $(50 \mu \mathrm{L})$, and Celgard membrane was used as the separator. The batteries were first left to stand for four hours to stabilize the interface before tests. Galvanostatic cycling was carried out on a standard battery tester (Neware CT-4008-5 V/10 mA). EIS and CV were conducted on an electrochemical workstation. CV was performed in the potential window from 2.5 to $3.8 \mathrm{~V}$ at a scan rate of $0.1 \mathrm{mV} \mathrm{s}^{-1}$.

\section{Results and discussion}

We employed a low-cost and facile brushing method to fabricate the $\mathrm{Na} @ \mathrm{SiO}_{2}$ composite electrode. The hydrophobic $\mathrm{SiO}_{2}$ used in this experiment is amorphous and the particle size is about $15 \mathrm{~nm}$ (Fig. S1†). Fig. 2a shows an optical photo and SEM image of a bare $\mathrm{Na}$ electrode, revealing a smooth, flat and shiny metallic surface. After brushing the nano $\mathrm{SiO}_{2}$, the surface of $\mathrm{Na}$ was evenly coated with a white layer of spherical nano-SiO particles (inset in Fig. 2b). Clearly, the fresh nano-SiO ${ }_{2}$ coating is highly porous (Fig. 2b), which promotes electrolyte diffusion and ion migration in nano-channel pores. ${ }^{\mathbf{4 1 - 4 5}}$ Due to the high viscosity of $\mathrm{Na}$, the nano- $\mathrm{SiO}_{2}$ particles are tightly attached to

a

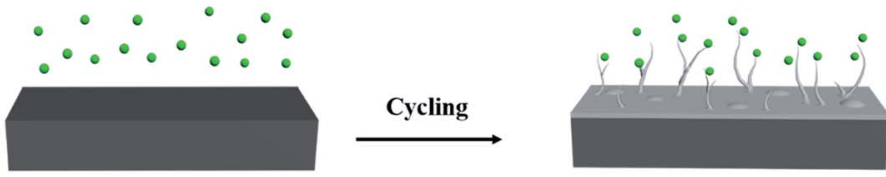

b
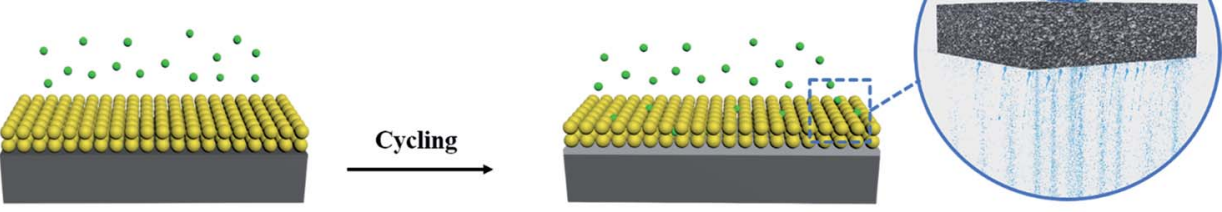

$\square$ Na-metal $\bigcirc$ Na-ion dendrite $\bigcup_{\text {Nano-SiO }}$

Fig. 1 Schematic illustrations of the Na stripping/plating behavior on (a) bare and (b) nano $\mathrm{SiO}_{2}$ coated $\mathrm{Na}$ electrodes. 

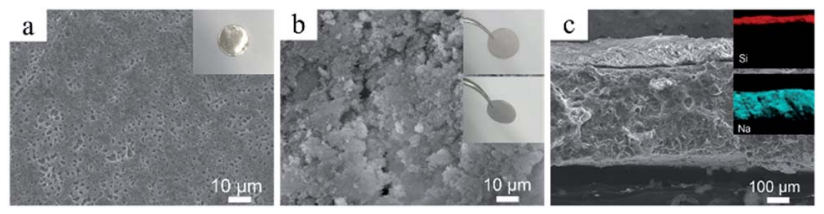

Fig. 2 The characterization of $\mathrm{Na}$ and $\mathrm{NaCSiO}$ electrodes. (a) Topview SEM image of a bare $\mathrm{Na}$ electrode and the corresponding digital image (inset). (b) Top-view SEM image of the $\mathrm{NaCSiO}_{2}$ electrode, and the corresponding top and side view digital images (insets). (c) Crosssectional SEM image of the $\mathrm{NaCSiO}_{2}$ electrode and the corresponding EDX elemental mapping images of $\mathrm{Si}$ and $\mathrm{Na}$ (insets).

the metal surface and will not fall off when the $\mathrm{Na@SiO}{ }_{2}$ electrode is inverted with tweezers (insets in Fig. 2b). As shown in Fig. 2c, the thickness of the nano- $\mathrm{SiO}_{2}$ coating is about $100 \mu \mathrm{m}$, which can be confirmed by EDX elemental mapping.

To assess the electrochemical performance of the ${\mathrm{Na} @ \mathrm{SiO}_{2}}_{2}$ electrode, symmetric cells with two identical $\mathrm{Na@SiO}$ electrodes were assembled in $1 \mathrm{M} \mathrm{NaPF}_{6} /$ diglyme electrolyte. For comparison, symmetric cells with two identical bare $\mathrm{Na}$ electrodes (thickness of $\sim 300 \mu \mathrm{m}$ ) were assembled.

Fig. 3a shows the galvanostatic cycling performance of symmetric cells with $\mathrm{Na@SiO}$ (yellow lines) and bare $\mathrm{Na}$ electrodes (green lines), respectively, for 400 cycles with a capacity of $1 \mathrm{~mA} \mathrm{~h} \mathrm{~cm}{ }^{-2}$ at 1,3 and $5 \mathrm{~mA} \mathrm{~cm}{ }^{-2}$. The symmetric cell with $\mathrm{Na} @ \mathrm{SiO}_{2}$ electrodes exhibited stable voltage profiles and much lower hysteresis $(5 \mathrm{mV})$ than the one with bare $\mathrm{Na}$ electrodes at 1 $\mathrm{mA} \mathrm{cm}{ }^{-2}$. The bare Na electrode displayed a gradual increase in hysteresis (>25 mV), where the overpotential increases first, and then irregularly fluctuates, indicating a micro-short circuit. ${ }^{46}$ When the current density was increased to $3 \mathrm{~mA} \mathrm{~cm}{ }^{-2}$, the $\mathrm{Na} @ \mathrm{SiO}_{2}$ electrode still exhibited a small overpotential $(15 \mathrm{mV})$ and very stable voltage profiles. In comparison, the symmetric cells with bare $\mathrm{Na}$ electrodes showed an anomalistic and apparently fluctuating voltage ( $>140 \mathrm{mV}$ ). As the current density was further increased to $5 \mathrm{~mA} \mathrm{~cm}{ }^{-2}$, the symmetrical cell with the bare Na electrode had large voltage polarization $(>180 \mathrm{mV})$ and obviously poor stability, which is due to the uneven plating/ stripping of Na metal, leading to the formation of dendrites. In contrast, the cell with the $\mathrm{Na}_{\mathrm{SSiO}}$ electrode not only exhibited a much lower polarization $(50 \mathrm{mV})$ but also realized very stable cycling under the same conditions. Furthermore, the rate behavior of the symmetric cells with bare $\mathrm{Na}$ and $\mathrm{Na} @ \mathrm{SiO}_{2}$ electrodes is presented in Fig. 3b. As the current density increased from 0.5 to $10 \mathrm{~mA} \mathrm{~cm}{ }^{-2}$, the voltage polarization of the bare $\mathrm{Na}$ electrode increased greatly and tended to be unstable, which was attributed to irregular growth of $\mathrm{Na}$ dendrites on the electrode surface. Unfortunately, when the current density returned to $0.5 \mathrm{~mA} \mathrm{~cm}{ }^{-2}$, the battery no longer returned to its previous state, indicating poor cycling stability. In contrast, the cell using the $\mathrm{Na}_{2} \mathrm{SiO}_{2}$ electrode continued to cycle steadily to $10 \mathrm{~mA} \mathrm{~cm}^{-2}$. It is worth mentioning that when the current density returned to $0.5 \mathrm{~mA} \mathrm{~cm}^{-2}$, the voltage profile was as stable as it was initially. To further demonstrate the

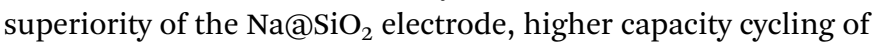
the symmetrical cell was performed and the results are



Fig. 3 Electrochemical performance of the $\mathrm{NaaSiO}_{2}$ electrode. (a) Comparison of cycling stability of bare $\mathrm{Na}$ (green) and $\mathrm{NaCSiO}_{2}$ electrodes (orange) in symmetrical cells at current densities of 1, 3 and $5 \mathrm{~mA} \mathrm{~cm}^{-2}$ with a capacity of $1 \mathrm{~mA} \mathrm{~h} \mathrm{~cm}^{-2}$. (b) Rate performance. (c) EIS plots of bare $\mathrm{Na}$ (left) and $\mathrm{Na}_{\mathrm{aSiO}}$ electrodes (right) in symmetrical cells after different cycles at a current density of $1 \mathrm{~mA} \mathrm{~cm}^{-2}$ with a capacity of $1 \mathrm{~mA} \mathrm{~h} \mathrm{~cm}^{-2}$.

presented in Fig. S2. $\dagger$ The result demonstrated that the stability of the $\mathrm{Na} @ \mathrm{SiO}_{2}$ electrode is significantly improved in virtue of the nano- $\mathrm{SiO}_{2}$ coating, which could induce a relatively uniform distribution of $\mathrm{Na}^{+}$flux over the entire Na surface..$^{26,45,47}$

Moreover, electrochemical impedance spectroscopy (EIS) was performed after 1,30 , and 50 cycles at a current density of 1 $\mathrm{mA} \mathrm{cm}{ }^{-2}$. The interfacial resistance of the SEI and surface charge transfer impedance of the electrode were estimated according to the diameter of the semicircle in the high frequency range. ${ }^{26,48}$ As shown in Fig. 3c, the Nyquist plots of the bare Na electrode show that the interface resistance increases after cycling ( $19 \Omega$ in the 1 st cycle, $25 \Omega$ in the 30 th cycle, and 35 $\Omega$ in the 50th cycle). This phenomenon is explained by the morphological transformation of the bare Na surface, indicating the occurrence of fractures in the SEI layer and the obvious growth of $\mathrm{Na}$ dendrites ${ }^{26}$ which is proven in the 
subsequent SEM images. In addition, the ontological impedance of the symmetric cells with bare $\mathrm{Na}$ increases as the number of cycles increases, which is due to the generation of a large amount of non-conductive material during repeated repair of the SEI layer process, thereby degrading the overall conductivity of the battery. ${ }^{49}$ The $\mathrm{Na} @ \mathrm{SiO}_{2}$ electrode exhibited a smaller semicircle after cycling, indicating that the charge transfer resistance of the $\mathrm{Na@SiO}{ }_{2}$ composite electrode is much lower than that of bare $\mathrm{Na}$. This could be attributed to the fact that the porous nano-SiO ${ }_{2}$ coating induced a relatively uniform distribution of $\mathrm{Na}^{+}$flux and a stable SEI layer was formed on the $\mathrm{Na}$ metal electrode surface, thereby achieving the purpose of suppressing the generation of Na dendrites. ${ }^{50}$

The morphological evolution of bare $\mathrm{Na}$ and $\mathrm{Na} @ \mathrm{SiO}_{2}$ electrodes after 100 cycles is shown in Fig. 4 . The bare Na electrode exhibited a rough surface with rugged and mossy Na deposition at a current density of $1 \mathrm{~mA} \mathrm{~cm} \mathrm{~cm}^{-2}$ (Fig. 4a), which differed from the fresh Na electrode morphology. When the current density was increased to 3 and $5 \mathrm{~mA} \mathrm{~cm} \mathrm{~cm}^{-2}$, the bare $\mathrm{Na}$ electrode showed an extremely inhomogeneous surface with excessive $\mathrm{Na}$ dendrites and dead $\mathrm{Na}$ (Fig. $4 \mathrm{~b}$ and $\mathrm{c}$ ). The morphological variation is mainly caused by the non-uniform $\mathrm{Na}$ plating/ stripping and high reaction kinetics on the surface of sodium metal. In contrast, the morphology of the $\mathrm{Na@SiO}{ }_{2}$ electrode retained a flat surface without any detectable protrusions (Fig. $4 \mathrm{~d}-\mathrm{f}$ ), which is attributed to the porous nano- $\mathrm{SiO}_{2}$ coating for homogenizing the distribution of $\mathrm{Na}^{+}$on the Na surface. The above morphological evolution results demonstrate the role of nano-SiO $\mathrm{S}_{2}$ coating in restraining $\mathrm{Na}$ dendritic growth.

In order to further study the deposition behavior of $\mathrm{Na}$ on the $\mathrm{Na} @ \mathrm{SiO}_{2}$ electrode, we further tested the $\mathrm{Na}$ metal electrode with conductive Super P coating (Na@Super P). The Super P used in this experiment is amorphous and the particle size is about $30 \mathrm{~nm}$ (Fig. S3†). The thickness of the Super P coating is about $100 \mu \mathrm{m}$ (Fig. S4†). The electrodes with $\mathrm{SiO}_{2}$ and Super $\mathrm{P}$ coatings all present small wetting angles (Fig. S5 $\dagger$ ), demonstrating excellent electrolyte permeability. Although both the $\mathrm{SiO}_{2}$ layer and Super $\mathrm{P}$ layer are porous coatings, in terms of electrochemical properties, the latter has lower cycling stability

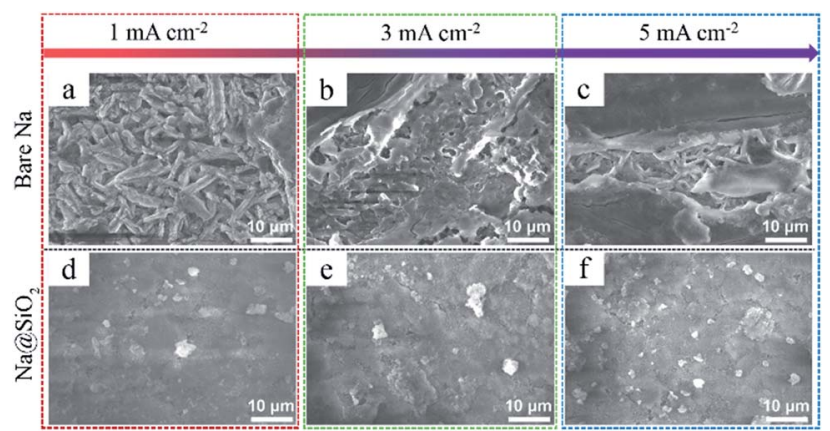

Fig. 4 Morphological evolution of bare $\mathrm{Na}$ and $\mathrm{NaCSiO}_{2}$ electrodes after cycling. SEM images of $(a-c)$ bare $\mathrm{Na}$ electrodes and $(\mathrm{d}-\mathrm{f})$ $\mathrm{NaASiO}_{2}$ electrodes after 100 stripping/plating cycles at different current densities, respectively. The current density is marked at the top of the figure and the stripping/plating capacity was $1 \mathrm{~mA} \mathrm{~h} \mathrm{~cm}{ }^{-2}$. than the former (Fig. 5a). The symmetric cells with the $\mathrm{Na} @ S u p e r \mathrm{P}$ electrodes exhibited larger voltage hysteresis after 55 h. As shown in Fig. 5b, no Na metal was found on the surface of the $\mathrm{SiO}_{2}$ coating after 50 cycles. We further proved that sodium metal was deposited at the bottom of the nano-SiO coating layer after battery cycling by a cross-sectional SEM test (Fig. S6†). However, Na metal appeared on the surface of the Na@Super P electrodes after 50 cycles (Fig. 5c). The surface of the bare $\mathrm{Na}$ electrode is no longer flat after 100 cycles (Fig. S7a $\dagger$ ), which is due to the formation of dendrites. The $\mathrm{Na} @ \mathrm{SiO}_{2}$ electrode is almost unchanged (Fig. S7b $\dagger$ ), while the Na@Super P electrode has changed from black to a metallic luster (Fig. S7c $\dagger$ ). The high conductivity of the Super P layer may weaken the position limiting ability on Na electrodeposition, leading to preferential deposition of $\mathrm{Na}$ above the conductive coating rather than below it. ${ }^{40}$ In contrast, owing to its electrically insulating properties, there should be a large variation of potential across the nano- $\mathrm{SiO}_{2}$ coating. ${ }^{51}$ Therefore, only the potential close to the surface of $\mathrm{Na}$ was low, and it was low enough for $\mathrm{Na}^{+}$to undergo a reduction reaction, forming a position-selective, bottom-up Na deposition process, instead of preferential deposition on Na protrusions/dendrite tips. ${ }^{52}$

To demonstrate the practical application of the $\mathrm{Na@SiO}$ electrode, we further assembled full cells with bare $\mathrm{Na}$ or $\mathrm{Na} @ \mathrm{SiO}_{2}$ as the anode and NVP as the cathode, respectively. The XRD profiles of NVP were consistent with PDF no. 70-3613 (Fig. S8a $\dagger$ ). The SEM image indicates that the NVP particles are cross-linked with CNTs (Fig. S8b $\dagger$ ).

A much higher NVP capacity was obtained with the $\mathrm{Na@SiO}$


exhibits superior capacities of 107, 99, 93, 89, 84, 80, 78, 76, 74


Fig. 5 (a) Comparison of the cycling stability of bare $\mathrm{Na}$ (green), $\mathrm{Na@SiO}$ (orange) and Na@Super $\mathrm{P}$ (gray) electrodes at a current density of $5 \mathrm{~mA} \mathrm{~cm} \mathrm{~cm}^{-2}$ with a capacity of $1 \mathrm{~mA} \mathrm{~h} \mathrm{~cm}{ }^{-2}$. Schematic illustrations and SEM images of (b) $\mathrm{NaCSiO}_{2}$ and (c) Na@Super $P$ electrodes after 50 stripping/plating cycles at a current density of $5 \mathrm{~mA}$ $\mathrm{cm}^{-2}$ with a capacity of $1 \mathrm{~mA} \mathrm{~h} \mathrm{~cm}^{-2}$. 

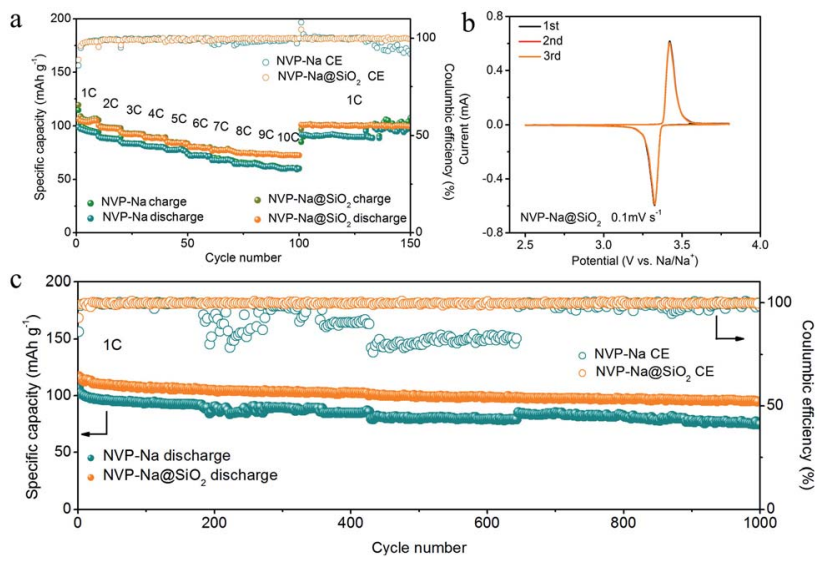

Fig. 6 Electrochemical performance of the full cells with bare $\mathrm{Na}$ or $\mathrm{NaCSiO}$ as the anode and NVP as the cathode. (a) Rate capability of the NVP-Na and NVP-Na( $\mathrm{SiO}_{2}$ cells at different rates from 1 to $10 \mathrm{C}$ $\left(1 \mathrm{C}=118 \mathrm{~mA} \mathrm{~g}^{-1}\right)$. (b) CVs of the NVP cathode at $0.1 \mathrm{mV} \mathrm{s}^{-1}$ coupled with the $\mathrm{NaCSiO}_{2}$ anode. (c) Cycling stability of full cells with the bare $\mathrm{Na}$ or $\mathrm{NaCSiO}$ anode at $1 \mathrm{C}$, respectively.

and $72.5 \mathrm{~mA} \mathrm{~h} \mathrm{~g}^{-1}$ with the current density increasing from 1 to 10C $\left(1 \mathrm{C}=118 \mathrm{~mA} \mathrm{~g}^{-1}\right)$, respectively. After 150 consecutive cycles, a capacity of $106 \mathrm{~mA} \mathrm{~h} \mathrm{~g}{ }^{-1}$ at $1 \mathrm{C}$ and an excellent coulombic efficiency of $99.4 \%$ are obtained. In contrast, the cells with bare Na anodes offer much lower capacities of 101, 89, 83, 80, 77, 72, 67, 64, 61 and $59 \mathrm{~mA} \mathrm{~h} \mathrm{~g}{ }^{-1}$ with pronounced instability. Fig. 6b shows the cyclic voltammograms (CVs) of the NVP electrode, in which there are evident redox pairs at $\sim 3.4 \mathrm{~V}$. Furthermore, when galvanostatically cycled at $1 \mathrm{C}$, the battery with the $\mathrm{Na@SiO}$ anodes presented much better cycling stability than the one with bare Na anodes. As shown in Fig. 6c, it is observed that the cell with the $\mathrm{Na} @ \mathrm{SiO}_{2}$ anode shows stable electrochemical performance $\left(94.6 \mathrm{~mA} \mathrm{~h} \mathrm{~g}^{-1}\right.$ after 1000 cycles, a capacity retention of $86.4 \%$, and a coulombic efficiency of $99.8 \%$ ). In sharp contrast, the cell with bare $\mathrm{Na}$ anodes exhibited a smaller initial discharge capacity of $100 \mathrm{~mA} \mathrm{~h} \mathrm{~g}^{-1}$, and only retained $74 \mathrm{~mA} \mathrm{~h} \mathrm{~g}{ }^{-1}$ after 1000 cycles with extremely unstable coulombic efficiency. The corresponding charge/ discharge voltage-capacity profiles at the 1st and 500th cycles are shown in Fig. S9, $\uparrow$ respectively. These results demonstrate the good adaptability of the $\mathrm{Na} @ \mathrm{SiO}_{2}$ anode in full cells.

\section{Conclusions}

In conclusion, we developed a low-cost and simple brushing method to improve the stripping/plating stability of Na metal anodes. The porous nano- $\mathrm{SiO}_{2}$ coating induces a relatively uniform distribution of $\mathrm{Na}^{+}$flux, resulting in uniform and dendrite-free deposition of metallic sodium. High cycling stability with low hysteresis was achieved in the $\mathrm{Na@SiO}$ electrode even at a very high current density of $5 \mathrm{~mA} \mathrm{~cm} \mathrm{~cm}^{-2}$. Furthermore, the $\mathrm{Na@SiO}$ |NVP full cell exhibits high cycling stability and superior suitability, making it far better than the full cell with bare $\mathrm{Na}$ as the anode. Our work provides an alternative route for the fabrication of safe $\mathrm{Na}$ metal anodes, which will be of great significance in the practical application of Na metal anodes for high-energy Na-based batteries.

\section{Conflicts of interest}

There are no conflicts of interest to declare.

\section{Acknowledgements}

This work was supported by the National Natural Science Foundation of China (51772257, 51702328 and 21805171), Major Basic Research Project of Shandong Natural Science Foundation (ZR2018ZC1459) and Shandong Natural Science Foundation (ZR2018BB038 and ZR2017BD002).

\section{Notes and references}

1 J. M. Tarascon and M. Armand, Nature, 2001, 414, 359-367.

2 J. W. Choi and D. Aurbach, Nat. Rev. Mater., 2016, 1, 16013.

3 Y. Zhao, K. R. Adair and X. Sun, Energy Environ. Sci., 2018, 11, 2673-2695.

4 J. Sun, Y. Lu, H. Yang, M. Han, L. Shao and J. Chen, Research, 2018, 2018, 6914626.

5 S. J. Tan, X. X. Zeng, Q. Ma, X. W. Wu and Y. G. Guo, Electrochem. Energy Rev., 2018, 1, 113-138.

$6 \mathrm{~J}$. Lu, Z. Chen, F. Pan, Y. Cui and K. Amine, Electrochem. Energy Rev., 2018, 1, 35-53.

7 G. Yang, H. Wang, B. Zhang, S. Foo, M. Ma, X. Cao, J. Liu, S. Ni, M. Srinivasan and Y. Huang, Nanoscale, 2019, 11, 9556-9562.

8 Y. He, C. Lu, S. Liu, W. Zheng and J. Luo, Adv. Energy Mater., 2019, 9, 1901810.

9 S. Liu, L. Deng, W. Guo, C. Zhang, X. Liu and J. Luo, Adv. Mater., 2019, 31, 1807585.

10 A. Ponrouch, D. Monti, A. Boschin, B. Steen, P. Johansson and M. R. Palacín, J. Mater. Chem. A, 2015, 3, 22-42.

11 D. Kundu, E. Talaie, V. Duffort and L. F. Nazar, Angew. Chem., Int. Ed., 2015, 54, 3431-3448.

12 X. Wang, L. Ma and J. Sun, ACS Appl. Mater. Interfaces, 2019, 11, 41297-41303.

13 D. Aurbach, Z. Lu, A. Schechter, Y. Gofer, H. Gizbar, R. Turgeman, Y. Cohen, M. Moshkovich and E. Levi, Nature, 2000, 407, 724-727.

14 Y. Liu, H. Kang, L. Jiao, C. Chen, K. Cao, Y. Wang and H. Yuan, Nanoscale, 2015, 7, 1325-1332.

15 C. Chen, T. Li, H. Tian, Y. Zou and J. Sun, J. Mater. Chem. A, 2019, 7, 18451-18457.

16 A. P. Cohn, N. Muralidharan, R. Carter, K. Share and C. L. Pint, Nano Lett., 2017, 17, 1296-1301.

17 K. Kretschmer, B. Sun, J. Zhang, X. Xie, H. Liu and G. Wang, Small, 2017, 13, 1603318.

18 B. Xiao, H. Liu, J. Liu, Q. Sun, B. Wang, K. Kaliyappan, Y. Zhao, M. N. Banis, Y. Liu, R. Li, T.-K. Sham, G. A. Botton, M. Cai and X. Sun, Adv. Mater., 2017, 29, 1703764.

19 N. Yabuuchi, K. Kubota, M. Dahbi and S. Komaba, Chem. Rev., 2014, 114, 11636-11682. 
20 R. Zhang, Y. Cui, W. Fan, G. He and X. Liu, Electrochim. Acta, 2019, 295, 181-186.

21 Y. Zhao, L. V. Goncharova, A. Lushington, Q. Sun, H. Yadegari, B. Wang, W. Xiao, R. Li and X. Sun, Adv. Mater., 2017, 29, 1606663.

22 H. Tian, Z. W. Seh, K. Yan, Z. Fu, P. Tang, Y. Lu, R. Zhang, D. Legut, Y. Cui and Q. Zhang, Adv. Energy Mater., 2017, 7, 1602528.

23 W. Luo and L. Hu, ACS Cent. Sci., 2015, 1, 420-422.

24 R. D. D. I. Iermakova, M. R. Palacín and A. Ponrouch, J. Electrochem. Soc., 2015, 166, 7060-7066.

25 X. Li, L. Zhao, P. Li, Q. Zhang and M. Wang, Nano Energy, 2017, 42, 122-128.

26 S. Chi, X. Qi, Y. Hu and L. Fan, Adv. Energy Mater., 2018, 8, 1702764.

27 N. Ingersoll, Z. Karimi, D. Patel, R. Underwood and R. Warren, Electrochim. Acta, 2019, 297, 129-136.

28 J. Lee, Y. Lee, J. Lee, S. M. Lee, J. H. Choi, H. Kim, M. S. Kwon, K. Kang, K. T. Lee and N. S. Choi, ACS Appl. Mater. Interfaces, 2017, 9, 3723-3732.

29 J. Zheng, S. Chen, W. Zhao, J. Song, M. H. Engelhard and J. Zhang, ACS Energy Lett., 2018, 3, 315-321.

30 Q. Liu, J. Xu, S. Yuan, Z. Chang, D. Xu, Y. Yin, L. Li, H. Zhong, Y. Jiang, J. Yan and X. Zhang, Adv. Mater., 2015, 27, 52415247.

31 W. Luo, C. Lin, O. Zhao, M. Noked, Y. Zhang, G. W. Rubloff and L. Hu, Adv. Energy Mater., 2017, 7, 1601526.

32 Y. Zhao, L. V. Goncharova, Q. Zhang, P. Kaghazchi, Q. Sun, A. Lushington, B. Wang, R. Li and X. Sun, Nano Lett., 2017, 17, 5653-5659.

33 J. Sun, C. Guo, Y. Cai, J. Li, X. Sun, W. Shi, S. Ai, C. Chen and F. Jiang, Electrochim. Acta, 2019, 309, 18-24.

34 Y. Lu, Q. Zhang, M. Han and J. Chen, Chem. Commun., 2017, 53, 12910-12913.

35 H. J. Yoon, N. R. Kim, H. J. Jin and Y. S. Yun, Adv. Energy Mater., 2018, 8, 1701261.

36 Q. Shi, Y. Zhong, M. Wu, H. Wang and H. Wang, Angew. Chem., 2018, 57, 9069-9072.
37 S. Liu, S. Tang, X. Zhang, A. Wang, Q. Yang and J. Luo, Nano Lett., 2017, 17, 5862-5868.

38 W. Luo, Y. Zhang, S. Xu, J. Dai, E. Hitz, Y. Li, C. Yang, C. Chen, B. Liu and L. Hu, Nano Lett., 2017, 17, 3792-3797.

39 J. Wang, J. Liu, Y. Cai, F. Cheng, Z. Niu and J. Chen, ChemElectroChem, 2018, 5, 1702-1707.

40 L. Kang, M. Cui, F. Jiang, Y. Gao, H. Luo, J. Liu, W. Liang and C. Zhi, Adv. Energy Mater., 2018, 8, 1801090.

41 H. Bian, J. Zhang, M. F. Yuen, W. Kang, Y. Zhan, D. Y. W. Yu, Z. Xu and Y. Y. Li, J. Power Sources, 2016, 307, 634-640.

42 S. J. R. Prabakar, J. Jeong and M. Pyo, Electrochim. Acta, 2015, 161, 23-31.

43 Y. Wang, H. Li, P. He, E. Hosono and H. Zhou, Nanoscale, 2010, 2, 1294-1305.

44 C. Wang, A. Wang, L. Ren, X. Guan, D. Wang, A. Dong, C. Zhang, G. Li and J. Luo, Adv. Funct. Mater., 2019, 29, 1905940.

45 C. Wei, R. Zhang, X. Zheng, Q. Ru, Q. Chen, C. Cui, G. Li and D. Zhang, Inorg. Chem. Front., 2018, 5, 3126-3134.

46 X. Han, Y. Gong, K. Fu, X. He, G. T. Hitz, J. Dai, A. Pearse, B. Liu, H. Wang, G. Rubloff, Y. Mo, V. Thangadurai, E. D. Wachsman and L. Hu, Nat. Mater., 2016, 16, 572.

47 N. Muralidharan, A. P. Cohn, R. Carter, K. Share and C. L. Pint, Nano Lett., 2017, 17, 1296-1301.

48 D. Lin, Y. Liu, Z. Liang, H. W. Lee, J. Sun, H. Wang, K. Yan, J. Xie and Y. Cui, Nat. Nanotechnol., 2016, 11, 626.

49 J. Meng, F. Chu, J. Hu and C. Li, Adv. Funct. Mater., 2019, 29, 1902220.

50 X. Q. Zhang, X. Chen, X. B. Cheng, B. Q. Li, X. Shen, C. Yan, J. Q. Huang and Q. Zhang, Angew. Chem., Int. Ed., 2018, 57, 5301-5305.

51 K. N. Wood, E. Kazyak, A. F. Chadwick, K. H. Chen, J. G. Zhang, K. Thornton and N. P. Dasgupta, ACS Cent. Sci., 2016, 2, 790-801.

52 D. D. Joshua, W. Gallaway, A. Gaikwad, C. Corredor, S. Banerjee and D. Steingart, J. Electrochem. Soc., 2010, 157, 1279-1286. 